\title{
Detection of butter adulteration with water using differential scanning calorimetry
}

\author{
Jolanta Tomaszewska-Gras
}

$3^{\text {rd }}$ Joint Czech-Hungarian-Polish-Slovak Thermoanalytical Conference Special Chapter

(c) The Author(s) 2011. This article is published with open access at Springerlink.com

\begin{abstract}
The study evaluated the applicability of differential scanning calorimetry (DSC) for the detection of water content in butter. High correlation coefficients were found between the water content and the enthalpies of the ice melting/water crystallization. The correlation equations were adopted to calculate the water content for seven tested kinds of butter, and the results were compared with the values, obtained by using the reference method. The difference between the water content determined by the reference method and by DSC ranged between 0.2 and $2.6 \%$ for the measured enthalpy of ice melting, and between 1 and $5.6 \%$ for the enthalpy of water crystallization. In relation to the data obtained, it can be concluded that the parameter of ice melting enthalpy can be used in the identification of adulterations or confirmation of butter authenticity.
\end{abstract}

Keywords Differential scanning calorimetry DSC .

Adulteration · Food · Butter · Water

\section{Introduction}

Differential scanning calorimetry (DSC) is extensively used in chemistry and physics to analyze, e.g. phase transitions of different compounds [1, 2]. Recently this technique has been used with increasing frequency to investigate food components as well as to detect food adulteration. Butter, due to its relatively high price, is frequently adulterated either with foreign fats (of animal or

J. Tomaszewska-Gras $(\bowtie)$

Department of Food Quality Management, Poznań University of Life Sciences, ul. Wojska Polskiego 31, 60-637 Poznan, Poland e-mail: gras@up.poznan.pl vegetable origin) or water. The name "butter" is reserved for a product containing max. $16 \%$ water in accordance with the Regulation of the Council (EC) no. 2991/1994 [3]. Adulteration of butter with water is at present detected using a reference method for the determination of water in butter, according to the standard [4]. Unfortunately, it is a highly time-consuming method. Studies conducted to date have shown applications of calorimetry to detect adulterations of edible fats with other, foreign fats [5-7]. The content of water can be measured with various techniques or methods. The DSC technique has been applied to analyze states of water, e.g., in such a biological system as food. With the use of this technique, phase transitions may be investigated, such as crystallization (measurement of energy released from the system), melting, or evaporation of water (measurement of energy absorbed during heating). Cooling curves constitute one of the simplest and most frequently used methods in the determination of freezing points of food; they have been used in the analysis of freezing point of milk [8] or tuna meat [9]. Numerous types of water are distinguished in food, such as bound water and free water, bulk water, or freezable water. Rahman [10] defined in the literature different states of water, such as bound, free, capillary, mobile, non-solvent, and unfreezable water. The concept of bound water was discussed as controversial by Wolfe et al. [11], who posed a question "what is unfreezable water, how unfreezable is it and how much is there?". Unfreezable water content was estimated also by comparing DSC endotherms of samples having freezable water from the plot of melting enthalpy as a function of water content in strawberries [12], dates [13], cabbage [14], and garlic [15]. If ice formation, i.e., the transition into the crystalline state, does not occur in subzero temperatures, then water is found in the so-called vitreous, i.e., amorphous state. It was shown that water 
passes into the vitreous state in different products at different temperatures, which is visible in thermograms by the baseline shift $[16,17]$. Another form in which water is found in food is the so-called unbound water, which during cooling undergoes crystallization, being seen as a narrow and sharp peak. Butter is a water-in-oil type emulsion, in which water exists as a dispersed hydrophilic substance not miscible with the hydrophobic fat phase. In studies, in which the phenomenon of the change in the state of aggregation of water is used for its quantitative determination, a relationship was proven between the amount of heat absorbed by the material during phase transition and the amount of water in this material. In accordance with the above, the amount of heat required to melt ice increased proportionally to the content of water in the system. The linear character of this dependency was even proven [16]. An example of an application of these results is, e.g., connected with the analysis of the content of free (freezable) water in beef muscles, conducted by Aktas et al. [18]. The behavior of water in the emulsion was also studied by DSC as a function of controlled dehydration of cheese spreads [19] or in crude oils [20].

The aim of this study was to present an attempt at the application of differential scanning calorimetry in the determination of water content in butter and next in the detection of butter adulteration with water. For this purpose, analyses were conducted on crystallization and melting of water contained in butter as well as water added to butter fat at different amounts. Repeatability of measurements and a relationship between enthalpy of melting and crystallization, and the amount of water in butter fat were also evaluated. An equation was also established for the calculation of water content using the enthalpy values of both crystallization and melting of water present in different amounts in butter.

\section{Experimental}

\section{DSC}

A Perkin Elmer DSC-7 was used to determine ice melting/ water crystallization temperatures and enthalpies. During all the measurements, dried nitrogen was used to purge the thermal analysis system (head and glove box). The device was calibrated using the standards of indium $\left(T_{\mathrm{m}}=\right.$ $156.60{ }^{\circ} \mathrm{C}, \Delta H=28.45 \mathrm{~J} \mathrm{~g}^{-1}$ ) and $n$-dodecane (99.8 purity, Merck, $T_{\mathrm{m}}=-9.65{ }^{\circ} \mathrm{C}$ ). Samples were weighed (in the range of $9-13 \mathrm{mg}$ ) to aluminum pans (50 $\mu \mathrm{L}$ total volume, Perkin Elmer) and hermetically sealed. The temperature regime involved two steps, i.e., cooling from 50 to $-40{ }^{\circ} \mathrm{C}$ and heating from -40 to $50{ }^{\circ} \mathrm{C}$; the scanning rate was $5{ }^{\circ} \mathrm{C} \min ^{-1}$. An empty pan was used as the reference sample. DSC analyses were performed in triplicate for every sample. The peak temperatures and enthalpies of water crystallization and ice melting were determined. The enthalpies were normalized per $1 \mathrm{~g}$ of the sample mass.

\section{Determination of the calibration curve}

The calibration curve was established on the basis of the enthalpy of ice melting/water crystallization. Samples were obtained by mixing with a homogenizer of different amounts of water $(5,10,15,20,25$, and $30 \%)$ with anhydrous butter fat $(\mathrm{w} / \mathrm{w})$.

Determination of water content using determined equations in different butter samples

Water content in seven different butters coming from different producers, with different water contents, was determined using the established equations. Moreover, in these samples, water content was also determined by the reference method [4].

\section{Statistical calculations}

The study comprised the analysis of correlation and its significance using STATISTICA 7.0 software. The index of relative standard deviation RSD (\%) was calculated as a ratio of standard deviation to the mean multiplied by 100 .

\section{Results and discussion}

DSC thermal analysis of crystallization and melting of butter

Figure 1 presents the curve of cooling and heating of butter with water content of $15.54 \%$. During butter cooling, peaks connected with the liquid-solid exothermic phase transition of fat and water may be observed. At a temperature of approx. $15^{\circ} \mathrm{C}$, the first-order transition corresponding to the crystallization of butter fat triacylglycerols occurred. Subsequently, at a temperature about $-20{ }^{\circ} \mathrm{C}$, there is a very intensive water crystallization phase transition, seen as a very sharp and narrow peak. Heat of the phase transition for water crystallization is approx. four times higher than that of butter fat crystallization $\left(\Delta H_{\text {fat }}=\right.$ approx. $75 \mathrm{~J} \mathrm{~g}_{\text {fat }}^{-1}, \Delta H_{\text {water }}=333.2 \mathrm{~J} \mathrm{~g}_{\text {water }}^{-1}$ ). Formation of ice in butter occurs at a temperature much lower than $0{ }^{\circ} \mathrm{C}$, i.e., from -20 to $-25{ }^{\circ} \mathrm{C}$, which is connected with the phenomenon of supercooling. Similar results of water crystallization temperature were reported in previous studys 
$[16,19]$. The effect of the presence of fat and other components, such as, e.g., protein, on a lowering of crystallization point is ambiguous, since for pure water the crystallization point was found to be $-22{ }^{\circ} \mathrm{C}$. In turn, in the process of butter heating (the melting curve, Fig. 1), endothermic transitions connected with the solid-liquid phase transition take place. At a temperature of approx. $-4.0{ }^{\circ} \mathrm{C}$, a symmetrical and narrow peak, slightly wider than that of crystallization, connected with ice melting can be observed. Further heating results in the appearance of smaller peaks, more broadened and with a gentle course, coming from melting of triacylglycerols contained in butter fat. Transition of fat melting ends at a temperature of approx. $35^{\circ} \mathrm{C}$, which corresponds to complete butter clarification and the presence of the liquid phase only.

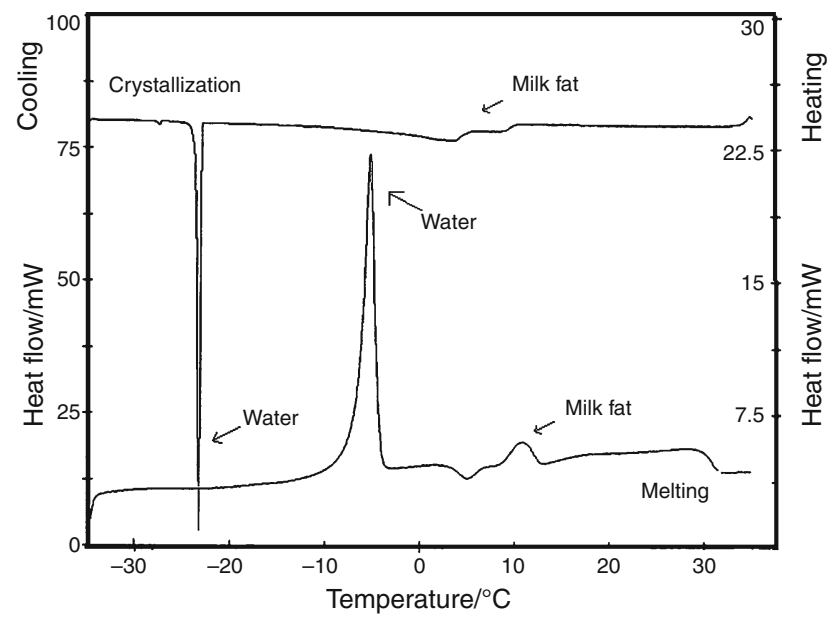

Fig. 1 DSC analysis of crystallization and melting process of butter containing $15.54 \%$ of water at scanning rate $5{ }^{\circ} \mathrm{C} \mathrm{min}-1$
Repeatability of results

Table 1 presents the results of analyses in terms of their repeatability, concerning temperature and enthalpy of ice melting and water crystallization in pure samples of butter, containing 15.54 and $21.33 \%$ water. Higher values of enthalpy of water crystallization and ice melting were recorded for the samples of butter with higher water contents. Repeatability of measurements was evaluated on the basis of relative standard deviation expressed in percent $(\%$ RSD). This is a relative measure of dispersion; thus, it facilitates a comparison of data with different distributions. Table 1 also compares the repeatability of DSC analysis for the three determinations of the same sample (three runs of melting and crystallization of the same sample) and for three samples prepared from the same butter batch. The aim of such a comparison is to verify the homogeneity of butter, as a material being a water-in-oil emulsion. Based on the results presented in Table 1 , it can be concluded that the standard deviations and RSD values for one sample analyzed three times were lower than the deviations for the three samples tested separately. However, these differences were not significant. Presented results show also that DSC measurements for temperature and enthalpy of water crystallization and ice melting points in butter samples are characterized by high repeatability at RSD ranging from 0.4 to $5.6 \%$ for the same sample repeated three times and from 2.4 to $4.8 \%$ for the three samples. Measurements of enthalpy during cooling and heating of butter samples had even lower RSD than those for temperature, i.e., from 0.5 to $1.2 \%$ for the same sample and from 2.2 to $4.5 \%$ for three samples. Moreover results presented in Table 1 showed that enthalpies of water crystallization and ice melting differ significantly $(P<0.05)$ for different amount of water $(15.54$ and $21.33 \%)$.

Table 1 Repeatability of DSC determinations of enthalpy and temperature of ice melting and water crystallization in butter samples with different amount of water

\begin{tabular}{|c|c|c|c|c|c|c|c|c|c|}
\hline & \multirow{3}{*}{$\begin{array}{l}\text { Sample weight/ } \\
\mathrm{mg}\end{array}$} & \multicolumn{4}{|l|}{ Crystallization } & \multicolumn{4}{|l|}{ Melting } \\
\hline & & \multicolumn{2}{|l|}{ Temperature $/{ }^{\circ} \mathrm{C}$} & \multicolumn{2}{|l|}{ Enthalpy $/ \mathrm{J} \mathrm{g}^{-1}$} & \multicolumn{2}{|c|}{ Temperature $/{ }^{\circ} \mathrm{C}$} & \multicolumn{2}{|c|}{ Enthalpy/J $\mathrm{g}^{-1}$} \\
\hline & & $T \pm \mathrm{SD}$ & $\begin{array}{l}\text { RSD/ } \\
\%\end{array}$ & $\Delta H \pm \mathrm{SD}$ & $\begin{array}{l}\text { RSD/ } \\
\%\end{array}$ & $T \pm \mathrm{SD}$ & $\begin{array}{l}\text { RSD/ } \\
\%\end{array}$ & $\Delta H \pm \mathrm{SD}$ & $\begin{array}{l}\mathrm{RSD} / \\
\%\end{array}$ \\
\hline \multirow{4}{*}{$\begin{array}{l}\text { Butter containing } 15.54 \% \\
\text { water }\end{array}$} & 10.60 & $-20.1 \pm 0.1$ & 0.4 & $-32.9 \pm 0.4$ & 1.2 & $-5.2 \pm 0.3$ & 5.6 & $34.6 \pm 0.2$ & 0.6 \\
\hline & 10.60 & $-21.4 \pm 0.5$ & 2.4 & $-32.4 \pm 0.7$ & 2.2 & $-5.1 \pm 0.1$ & 2.4 & $34.0 \pm 1.1$ & 3.3 \\
\hline & 12.07 & & & & & & & & \\
\hline & 11.44 & & & & & & & & \\
\hline \multirow{4}{*}{$\begin{array}{l}\text { Butter containing } 21.33 \% \\
\text { water }\end{array}$} & 11.25 & $-20.8 \pm 0.25$ & 1.2 & $-51.6 \pm 1.1$ & 2.1 & $-4.6 \pm 0.1$ & 2.4 & $54.4 \pm 0.3$ & 0.5 \\
\hline & 11.25 & $-21.7 \pm 0.9$ & 4.1 & $-53.8 \pm 2.1$ & 3.9 & $-4.8 \pm 0.2$ & 4.8 & $56.9 \pm 2.6$ & 4.5 \\
\hline & 9.18 & & & & & & & & \\
\hline & 9.36 & & & & & & & & \\
\hline
\end{tabular}

$R S D$ Relative standard deviation/\%, $\pm S D$ standard deviation for $n=3$ 
Enthalpy of ice melting/water crystallization depending on water content in butter

In order to investigate the dependence between the enthalpy and the water content in butter, samples of anhydrous butter fat were homogenized with water at the following concentrations: 5, 10, 15, 20, 25, and 30\% (w/w). Water crystallization and ice melting points, as well as changes in enthalpy depending on the level of water content are presented in Table 2. On the basis of temperature values presented in Table 2, it may be observed with regularity that the temperatures of water crystallization and ice melting increase with an increase in the water content, for cooling by approx. $4{ }^{\circ} \mathrm{C}$ and for melting by approx. $2^{\circ} \mathrm{C}$. Regarding the enthalpy it may be stated that the lower the water content, the lower the enthalpy of water crystallization and ice melting. Such dependence was already found in earlier studies, where it was stated that the level of enthalpy for each of the processes, i.e., melting and crystallization, is linearly dependent on the amount of the substance [16, 19]. A decreasing size of peaks for water crystallization or ice melting, and as a result-also enthalpy, is connected with two phenomena, i.e., the decreasing percentage of water in the sample, as well as changing properties of water. The value of enthalpy was analyzed as converted for the amount of water contained in the sample, and it turned out that this value drops from approx. $300 \mathrm{~J} \mathrm{~g}^{-1}$ for a $30 \%$ water content in the sample (which is close to the value of enthalpy for pure water) to approx. $180 \mathrm{~J} \mathrm{~g}^{-1}$ for a $5 \%$ water content. These data will be presented in a separate article. A similar phenomenon was also observed when investigating the level of cheese hydration [19]. By comparing the enthalpy of water crystallization and ice melting, can be observed that these values are not equal for the same water concentrations. Enthalpy values of water crystallization are always lower than those of melting enthalpy for the corresponding concentrations, which may result from the fact that crystallization occurs in a very rapid way, and some data may be lost during the measurement.

\section{Calibration curve}

On the basis of the above observations, an analysis was conducted on the correlation between the enthalpy and the water content in butter fat to determine the calibration curve for the calculation of the water content in butter samples. Correlation curves between enthalpies and water content together with correlation equations are presented in Fig. 2. Close correlations statistically significant at the significance level $\alpha=0.001$ were found. Correlation coefficient $(r)$ obtained for a dependence of "water content-enthalpy of ice melting" was $r=0.99$ and for "water content-enthalpy of water crystallization", $r=-0.98$. Extrapolation of lines presented in Fig. 2 to values of enthalpy $(\Delta H)$ equal to zero provides information on the amount of water, which may not crystallize, thus yielding

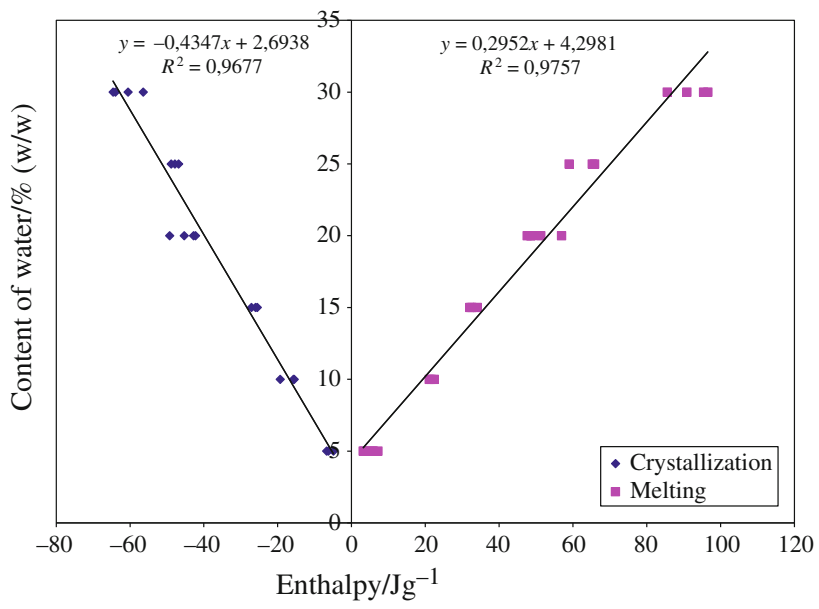

Fig. 2 Relationship between the content of water and enthalpy of ice melting and water crystallization in samples containing 5, 10, 15, 20, and $30 \%$ of water in butter fat

Table 2 Enthalpies and temperatures of ice melting and water crystallization in samples of butter fat mixed with 5, 10, 15, 20, 25, and 30\% water

\begin{tabular}{|c|c|c|c|c|c|c|c|c|}
\hline \multirow[t]{3}{*}{ Water content in butter fat $/ \%$} & \multicolumn{4}{|l|}{ Crystallization } & \multicolumn{4}{|l|}{ Melting } \\
\hline & \multicolumn{2}{|c|}{ Temperature $/{ }^{\circ} \mathrm{C}$} & \multicolumn{2}{|c|}{ Enthalpy/J $\mathrm{g}^{-1}$} & \multicolumn{2}{|c|}{ Temperature $/{ }^{\circ} \mathrm{C}$} & \multicolumn{2}{|c|}{ Enthalpy/J g $\mathrm{g}^{-1}$} \\
\hline & $T \pm \mathrm{SD}$ & $\mathrm{RSD} / \%$ & $\Delta \mathrm{H}+\mathrm{SD}$ & $\mathrm{RSD} / \%$ & $T \pm \mathrm{SD}$ & $\mathrm{RSD} / \%$ & $\Delta \mathrm{H}+\mathrm{SD}$ & $\mathrm{RSD} / \%$ \\
\hline 5 & $-26.4 \pm 0.4$ & 1.4 & $-5.9 \pm 0.9$ & 15.8 & $-5.1 \pm 0.1$ & 2.3 & $5.5 \pm 0.6$ & 10.2 \\
\hline 10 & $-24.6 \pm 1.0$ & 4.2 & $-16.9 \pm 2.1$ & 12.7 & $-4.5 \pm 0.2$ & 4.5 & $21.7 \pm 0.7$ & 3.2 \\
\hline 15 & $-24.6 \pm 1.1$ & 4.4 & $-26.2 \pm 0.8$ & 3.1 & $-3.9 \pm 0.4$ & 9.3 & $32.9 \pm 1.0$ & 3.1 \\
\hline 20 & $-23.8 \pm 2.1$ & 8.8 & $-44.9 \pm 3.2$ & 7.1 & $-3.8 \pm 0.05$ & 1.3 & $50.6 \pm 3.8$ & 7.5 \\
\hline 25 & $-21.1 \pm 1.6$ & 7.4 & $-47.8 \pm 1.0$ & 2.1 & $-3.9 \pm 0.03$ & 0.8 & $63.4 \pm 3.8$ & 6.1 \\
\hline 30 & $-23.0 \pm 1.5$ & 6.6 & $-61.4 \pm 3.7$ & 6.1 & $-3.6 \pm 0.1$ & 4.1 & $92.1 \pm 5.0$ & 5.4 \\
\hline
\end{tabular}

$R S D$ relative standard deviation/\%, $\pm S D$ standard deviation for $n=3$ 
Table 3 Comparison of water contents determined in butter samples using the reference method and the DSC method (correlation equations)

\begin{tabular}{|c|c|c|c|c|c|c|c|}
\hline \multirow[b]{2}{*}{ Sample } & \multirow[b]{2}{*}{$\begin{array}{l}\text { Water content } \\
\text { determined } \\
\text { by reference } \\
\text { method/\% }\end{array}$} & \multicolumn{3}{|l|}{ Crystallization } & \multicolumn{3}{|l|}{ Melting } \\
\hline & & $\begin{array}{l}\text { Enthalpy } \\
\Delta \mathrm{H} / \mathrm{J} \mathrm{g}^{-1}\end{array}$ & $\begin{array}{l}\text { Water content } \\
\text { calculated from } \\
\text { equation: } \% \mathrm{H}_{2} \mathrm{O}= \\
2.6938-0.4347 \times \Delta \mathrm{H}\end{array}$ & $\begin{array}{l}\text { Accuracy of } \\
\text { DSC analysis }\end{array}$ & $\begin{array}{l}\text { Enthalpy } \\
\Delta \mathrm{H} / \mathrm{J} \mathrm{g}^{-1}\end{array}$ & $\begin{array}{l}\text { Water content } \\
\text { calculated from } \\
\text { equation: } \% \mathrm{H}_{2} \mathrm{O}=4.2981 \\
+0.2952 \times \Delta \mathrm{H}\end{array}$ & $\begin{array}{l}\text { Accuracy of } \\
\text { DSC analysis }\end{array}$ \\
\hline Butter 1 & $15.2 \pm 0.2$ & $-31.1 \pm 0.7$ & 16.2 & 1.0 & $37.7 \pm 1.1$ & 15.4 & 0.2 \\
\hline Butter 2 & $15.3 \pm 0.1$ & $-31.3 \pm 0.1$ & 16.3 & 1.0 & $34.6 \pm 1.7$ & 14.5 & 0.8 \\
\hline Butter 3 & $15.5 \pm 0.2$ & $-32.4 \pm 0.7$ & 16.8 & 1.3 & $34.0 \pm 1.1$ & 14.3 & 1.2 \\
\hline Butter 4 & $21.3 \pm 0.6$ & $-53.8 \pm 2.1$ & 26.1 & 4.8 & $56.9 \pm 2.6$ & 21.1 & 0.2 \\
\hline Butter 5 & $32.1 \pm 0.3$ & $-64.9 \pm 5.3$ & 30.9 & 1.2 & $85.5 \pm 0.6$ & 29.5 & 2.6 \\
\hline Butter 6 & $24.1 \pm 0.1$ & $-62.2 \pm 7.7$ & 29.7 & 5.6 & $71.8 \pm 3.4$ & 25.5 & 1.4 \\
\hline Butter 7 & $26.1 \pm 0.0$ & $-62.1 \pm 6.1$ & 29.7 & 3.6 & $72.2 \pm 2.1$ & 25.6 & 0.5 \\
\hline Mean & & & & 2.6 & & & 1.0 \\
\hline
\end{tabular}

$\pm S D$ Standard deviation for $n=3$

no peak originating from crystallization of water or ice melting.

Determination of water content in butter samples based on calibration curves

On the basis of equations established for the dependencies of "water content-enthalpy of ice melting" and "water content-enthalpy of water crystallization" (Fig. 2), the content of water was calculated for seven purchased butters coming from different producers. The actual content of water in those samples was determined using the reference method [4]. Results are presented in Table 3. On the basis of the established difference in the contents of water between the determination by the reference method and that by DSC, the accuracy of the determinations of the water content provided by this technique can be established. It was observed that for the water content in butter within the range of 15-32\%, accuracy ranged from 0.2 to $2.6 \%$ for the enthalpy of melting, while for crystallization these values were slightly higher, i.e., from 1 to $5.6 \%$. The mean value for accuracy for the seven tested samples of butter was $1 \%$ in case of the analysis of the melting process or $2.6 \%$ for crystallization. These values indicate that a higher accuracy of determinations is provided for the analysis of ice melting in butter samples than in the process of water crystallization. A linear graph, analogous to that in Fig. 2, was prepared for correlations of butter samples (results presented in Table 3) between enthalpy of water crystallization/ice melting, and the actual water content in seven analyzed butter samples (determined by the reference method). The obtained equations in Fig. 3 are similar to those of calibration curves, presented in Fig. 2.

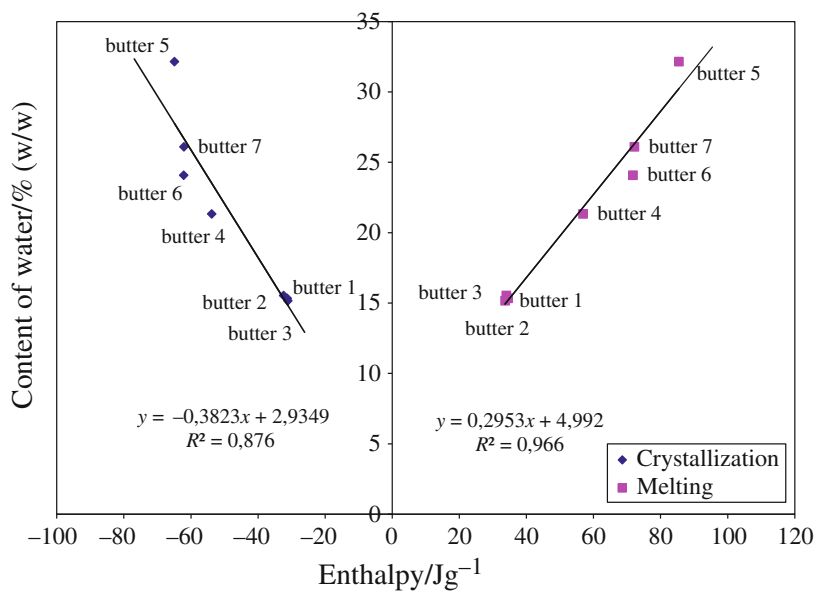

Fig. 3 Relationship between the content of water determined by reference method and enthalpy of ice melting and water crystallization in seven kinds of butter

\section{Conclusions}

It results from the presented analyses that the DSC technique for the processes of water crystallization and ice melting in the water-in-oil emulsion, such as butter, is characterized by a high repeatability of measurements both for temperature and enthalpy. The obtained mean index of RSD for all measurements of enthalpy of water crystallization was $4.8 \%$, while for melting it was $4.2 \%$. For water crystallization and ice melting temperatures, they were 5.4 and $3.7 \%$, respectively. These data indicate that the DSC technique may be considered as a thermoanalytic technique in the analyses of organic origin materials such as, e.g., food.

Results also showed that there is a linear dependence between the enthalpy of phase transitions of water 
(crystallization, melting) and its content in samples of butter within the investigated range of $5-30 \%$ water concentrations. Decrease in the enthalpy with a decrease in the water content results not only from the reduction of the percentage content of water in the sample, but also from changing properties of water with a reduction of its content in butter. In view of the higher accuracy of water determinations in butter samples based on the measurement of enthalpy of ice melting (at 1\%) than the measurement of enthalpy of crystallization (at 3\%) and the fact that crystallization is a metastable process, which is occasionally manifested in more than one crystallization peaks, practical applications may be considered for this method of determinations of melting enthalpy in the identification of butter adulterations within a time period much shorter than that in the reference method. The final confirmation of the suitability of DSC in the determination of water content in butter requires further studies concerning the repeatability of determinations and the calibration curve for the purpose of quantitative evaluation of adulterations. This method may prove to be more attractive if it turned out to be possible with the use of this technique to detect adulteration of butter with foreign fats. In such a case, at one determination, it would be possible to confirm authenticity of butter in terms of water content and the presence of foreign fats.

Acknowledgements The author wishes to thank the Polish State Committee for Scientific Research who financed this research project No, NN 312260538.

Open Access This article is distributed under the terms of the Creative Commons Attribution Noncommercial License which permits any noncommercial use, distribution, and reproduction in any medium, provided the original author(s) and source are credited.

\section{References}

1. Śliwińska-Bartkowiak M, Gras J, Sikorski R, Radhakrishnan R, Gelb LD, Gubbins KE. Phase transitions in pores: experimental and simulations studies of melting and freezing. Langmuir. 1999;15:6060-9.

2. Śliwińska-Bartkowiak M, Gras J, Sikorski R, Dudziak G, Radhakrishnan R, Gubbins KE. Experimental and simulation studies of melting and freezing in porous glasses. Stud Surf Sci Catal. 2000;128:141-50.

3. COUNCIL REGULATION (EC) No 2991/94 of 5 December 1994 laying down standards for spreadable fats.
4. EN ISO 3727-1:2004 Butter - the determination of water content, fat-free dry mass and fat-Part 1: determination of water content (reference method).

5. Aktas N, Kaya M. Detection of beef body fat and margarine in butterfat by differential scanning calorimetry. J Therm Anal Calorim. 2001;66:795-6.

6. Lörinczy D, Regdon JG, Keller B, Szakály S, Schäffer B. Development of a DSC method for determination of certain technological parameters of margarine and mixed-fat spread. J Therm Anal Calorim. 2007;88:351-4.

7. Chiavaro E, Vittadini E, Rodriguez-Estrada MT, Cerretani L, Bendini A. Differential scanning calorimeter application to the detection of refined hazelnut oil in extra virgin olive oil. Food Chem. 2008;110:248-56.

8. Chen P, Chen XD, Free KW. Measurement and data interpretation of the freezing point depression of milks. J Food Eng. 1996;30:239-53.

9. Rahman MS, Kasapis S, Guizani N, Al-Amri O. State diagram of tuna meat: freezing curve and glass transition. J Food Eng. 2003;57:321-6.

10. Rahman MS. State diagram of foods: Its potential use in food processing and product stability. Trends Food Sci Tech. 2006; 17:129-41.

11. Wolfe J, Bryant G, Koster KL. What is 'unfreezable water', how unfreezable is it, and how much is there? CryoLetters. 2002; 23:157-66.

12. Roos YH. Effect of moisture on the thermal behavior of strawberries studied using differential scanning calorimetry. J Food Sci. 1987;52:146-9.

13. Rahman MS. State diagram of date flesh using differential scanning calorimetry (DSC). Int J Food Prop. 2004;7:407-28.

14. Paakkonen K, Plit L. Equilibrium water content and the state of water in dehydrated white cabbage. J Food Sci. 1991;56:1597-9.

15. Rahman MS, Sablani SS, Al-Habsi N, Al-Maskri S, Al-Belushi R. State diagram of freeze-dried garlic powder by differential scanning calorimetry and cooling curve methods. J Food Sci. 2005;70:E135-41.

16. Simatos D, Faure M, Bonjour E, Couach M. Differential thermal analysis and differential scanning calorimetry in the study of water in foods. In: Duckworth R, editor. Water relations of foods. London/New York/San Fransisco: Academic Press; 1974. p. 193-209.

17. Tomaszewska-Gras J, Kijowski J. The application of differential scanning calorimetry DSC to assess thermodynamic properties of bee honey and substances used in its adulteration. Sci Nat Technol. 2010;4:\#26.http://www.npt.up-poznan.net/tom4/zeszyt2/art_26.pdf.

18. Aktas N, Tülek Y, Gökalp HY. Determination of freezable water content of beef semimembranous muscle. DSC study. J Therm Anal Calorim. 1997;48:259-66.

19. Gliguem H, Ghorbel D, Grabielle-Madelmont C, Goldschmidt B, Lesieur S, Attia H, Ollivon M, Lesieur P. Water behavior in processed cheese spreads. DSC and ESEM study. J Therm Anal Calorim. 2009;98:73-82. doi:10.1007/s10973-009-0376-x.

20. Díaz-Ponce JA, Flores EA, Lopez-Ortega A, Hernández-Cortez JG, Estrada A, Castro LV, Vazquez F. Differential scanning calorimetry characterization of water-in-oil emulsions from Mexican crude oils. J Therm Anal Calorim. 2010;102:899-906. doi:10.1007/s10973-010-0904-8. 